\title{
Challenges and needs for China to eliminate rabies
}

Wenwu Yin ${ }^{1,2^{*}+}$, Jie Dong ${ }^{6 \dagger}$, Changchun Tư ${ }^{4}$, John Edwards ${ }^{5}$, Fusheng Guo ${ }^{5}$, Hang Zhou ${ }^{1}$, Hongjie Yu ${ }^{1,2}$, Sirenda Vong ${ }^{3}$ and for the Rabies Technical and Advisory Board ${ }^{\dagger}$

\begin{abstract}
In China, rabies is a significant public health concern where dogs remain the main reservoir of disease transmission to humans; rabies-related mortality ranks second in the world.

We compiled all published articles and official documents on rabies in mainland China to examine challenges and needs to eliminate rabies in the country. The Chinese authorities have identified rabies as a priority, recognized rabies control in dogs as key to control rabies in humans and required intersectoral collaborations. Efforts have been made to respond effectively to the latest re-emergence of rabies, which peaked in 2007 with $>3,300$ cases. Despite these outcomes and the increasing volume of publications and regulations in the recent years, our review points to some major information gaps to improve rabies control activities and envisage elimination program. An emphasis on laboratory or pathogen-associated and basic epidemiology research in the literature has contrasted with the absence of information to monitor various systems in humans and animals (e.g. quality of surveillance, response and post-exposure prophylaxis). Information is also lacking to appropriately inform policymakers (e.g. economic disease burden, impact of policies) and assist program managers (e.g. comprehensive and strategic guidance for cost-effective prevention and control activities, public education and dog population management).

In conclusion, strategic planning is needed to provide a sense of direction, demonstrate feasibility of elimination in China, and develop a research agenda, addressing country's operational needs and constraints. The planning should be a multisectoral effort.
\end{abstract}

Keywords: Rabies, Elimination, China, Needs, Challenges, Review

\section{Multilingual abstracts}

Please see Additional file 1 for translations of the abstract into the six official working languages of the United Nations.

\section{Introduction}

Despite the existence of an effective vaccine, rabies remains a public health problem worldwide, especially in developing countries. Around 3.9 billion people are atrisk, and approximately 55,000 people die of rabies each year worldwide and $>150$ countries are affected. China is a high-risk environment for rabies, with the number of

\footnotetext{
* Correspondence: yinww@chinacdc.cn

${ }^{\dagger}$ Equal contributors

'Division of Infectious Diseases, Chinese Center for Disease Control and Prevention, Beijing, China

${ }^{2}$ Key Laboratory of Surveillance and Early-warning on Infectious Disease,

Chinese Center for Disease Control and Prevention, Beijing, China Full list of author information is available at the end of the article
}

related deaths being second only to India and where dogs continue to serve as the main reservoir of disease transmission to humans [1]. For the past decade, China has faced a reemergence of the disease, rabies being currently reported among the top three causes of human death due to infectious diseases [2].

There has been evidence that canine rabies elimination is feasible in many countries [3-7]. This has happened through implementation of strict dog population control measures and synchronized mass dog vaccination, in Central and South America [8]. In Asia, rabies has been controlled or eliminated for decades in Malaysia, Japan and many island countries or regions [5]. There is a growing global momentum for elimination of canine rabies through the formation of the Global Alliance for Rabies Control and the Partners for Rabies Prevention Group [9]. In South Asia, many recent efforts have been made for canine rabies elimination through coalitions

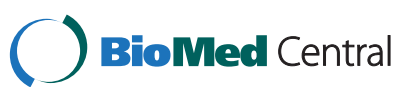


and partnerships between regional institutions, as recommended by the FAO and WHO. The Association of Southeast Asian Nations (ASEAN) and the South Asian Association for Regional Cooperation (SAARC) adopted the resolution to prevent and control rabies, with the goal of rabies elimination by year 2020 [9]. It is widely recognized that rabies elimination requires an integrated approach by animal and human related services. There is growing support for the use of progressive control pathway strategy to achieve elimination of rabies (de Balogh K, unpublished observation). This strategy is particularly well suited to countries that are large and diverse. We reviewed the literature to assess the current situation in China with a special of focus on identifying future needs to control human rabies through eliminating canine rabies. This report describes the results of this work.

\section{Review}

Methods

Rabies Advisory and Technical Board (RATB)

Under the United National Theme Group on Health [10] Sub-working Group on Diseases at the Human-Animal Interface in China, the World Health Organization (WHO) and Food and Agriculture Organization (FAO) have sponsored and served as Secretariats of a Board which consists of independent national rabies specialists in public health, veterinary science, clinical medicine, and laboratory sciences. These experts are in-country advocates for best practices and research in rabies control and elimination in China. The Board meets twice a year to assess various aspects of rabies prevention and control in the country [11].

\section{Guiding principles for rabies elimination}

Rabies virus belongs to the lyssavirus genus, which also includes other lyssavirus species that cause rabies-like diseases and can be carried by domestic animals, wild carnivores and many bats species. However, the rabies virus is the only pathogen responsible for the large majority of rabies cases in humans. Of utmost importance, this virus is typically perpetuated solely by domestic dogs, which makes elimination of rabies virus realistic $[4,6]$. Therefore the paradigm of rabies control in humans is driven by interrupting rabies virus circulation in the dog population through mass vaccination (i.e. aim to achieve $70 \%$ vaccination coverage threshold) [12]. Elimination of rabies is feasible and cost effective $[4,7,13]$. The progressive roadmap to reaching elimination status lies on three pillars. The first one is the control of rabies in dogs; the second is to provide full access to adequate post-exposure prophylaxis (PEP) in humans, and lastly is to ensure effective disease and animal reservoir surveillance throughout the course of the campaign. Rabies elimination occurs solely through a multisectoral approach and above all, effective implementation requires sustained political commitment from all levels and sectors of the government; integration of the health, livestock and local government system; and through the partnership and involvement of community members and those engaged with education and the environment.

\section{Literature review}

We searched (1) the Pubmed database (1963-2012) using the following search terms "rabies" [MeSH Terms] OR "rabies" [All Fields]) OR "animal bites" [Titles/Abstracts] AND China [Affiliation] NOT Taiwan [Affiliation]) NOT Hong Kong [Affiliation]) NOT Macau [Affiliation] and (2) wanfang.med.online, a Chinese Database (3)baidu.com, a Chinese search-engine, and (4) official government websites using the same keywords. We manually screened titles and abstracts to exclude all papers related to non-death associated animal bites, rabies virus basic microbiology and rabies virus as gene therapy vectors. The full texts of the eligible papers were accessed. We also contacted officials from the Ministries of Health and Agriculture and other agencies involved in rabies-related activities and requested national reports/guidelines, proceedings and unpublished observations (oral presentations).

In this report, we analyzed the Chinese rabies situation and presented the results of the review using the following categories: (1) epidemiological situation; (2) level of awareness; (3) control in humans; (4) prevention and control in animals and; (5) surveillance in humans and dogs.

\section{Results}

The literature search identified 201 reports of interest including 189 articles from Pubmed and 12 official documents (guidelines/protocols, legislative documents, and official notices/reports).

Scientific publications on rabies have increased by tenfold in China since 2003, particularly in English language ( $\mathrm{n}=114,60.3 \%)$ journals. This indicates renewed attention given to a commonly neglected disease (Figure 1a), probably due to the latest disease re-emergence and increased international interest. The different categories of rabies-related publications are presented in Table 1 . The key results included the contrast between an emphasis on laboratory or pathogen-associated and basic epidemiology research and the lack of research (1) for effective policies, (2) to analyze system-wide issues (surveillance, response, PEP clinics quality and coverage) or (3) improve existing control interventions in humans and animals (Figure 1b).

\section{Epidemiological situation}

The latest resurgence of human rabies cases occurred in 1997 - 2001, notably in southern and eastern provinces, 

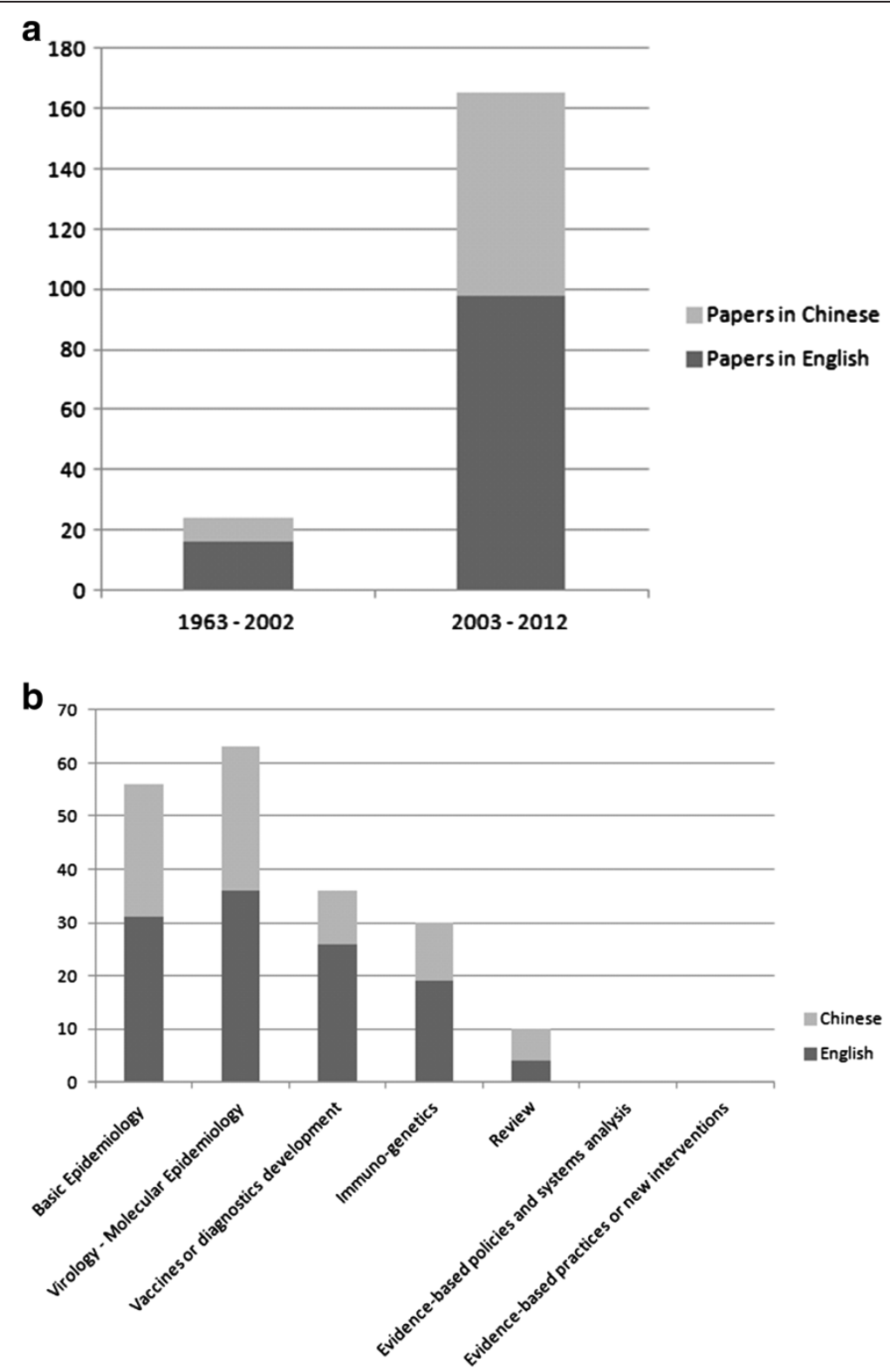

Figure 1 Rabies related publications in China, 1963-2012. (a) categorized by period; (b) categorized by type of outputs.

reaching a peak of 3,300 cases in 2007 (Figure 2). In $2011,86 \%$ of the human cases lived from farming families in rural area including farmers $(69.5 \%)$ and children (16.5\%). Patients died of rabies mostly from $\operatorname{dog}(95 \%)$ and cat (4\%) bites. Of these, $77 \%$ did not have wound cleaning in clinics and 91\% did not have timely or appropriate PEP. Most (51\%) human cases were reported from five southern provinces (i.e. Guizhou, Guangxi, Hunan, Guangdong and Yunnan) [2].

In China, all reports of lyssavirus isolates but one (i.e. non-RABV virus in bats in Jilin Province) [14] have been $\mathrm{RABV}$, of which all were from the classic genotype I, which pertains to viruses found in dogs on all continents.
Although wildlife rabies investigation is quite limited in China, it is thought that wildlife rabies (e.g. in ferret badgers) stem from spillover from dogs [15-17]; however, some strains isolated from ferret badgers were only identified in limited areas of Zhejiang and Jiangsu provinces showed only $89 \%$ of phylogenetic similarity with local dog viruses and was closer to a dog variant of Southern China [18]. This could be an independent wildlife cycle that could preclude country-wide elimination [18,19]. Investigations in the wildlife, which also include bats need to continue.

In China, authors believed that rabies epidemic may have a 10 year-cycle, and that reductions can be attributed 
Table 1 Distribution of rabies-related scientific articles from Mainland China by category group, $1963-2012$

\begin{tabular}{|c|c|c|c|c|}
\hline & \multicolumn{4}{|c|}{ Scientific articles } \\
\hline & $\begin{array}{c}\text { In } \\
\text { English, } \\
\mathrm{n}=114\end{array}$ & $\begin{array}{c}\text { In } \\
\text { Chinese, } \\
\mathrm{n}=75\end{array}$ & $\begin{array}{c}\text { Total, } \\
\mathrm{N}=189\end{array}$ & $\%$ \\
\hline
\end{tabular}

\section{Journal type}

General

Human

Animal

Sector

$$
\text { Human }
$$

General

Setting

Lab-based
Clinical/facility-based
Urban community based
Urban-Rural (mixed)
Occupational

Rural community based

Species

Pathogen
Human
Dog
Multiple animals
Immuno-genetics
Basic epidemiology
Case studies or outbreak
reports in humans and
animals
Seroprevalence in animals
Surveillance data and risk
factors
*PEP patients' analysis
Costs of treatment
Level of awareness in
public and health care
workers

Vaccines and diagnostics development

Virology - Molecular epidemiology

Virology

Review

Evidence based policies and systems analysis
Table 1 Distribution of rabies-related scientific articles from Mainland China by category group, 1963 - 2012

\begin{tabular}{|c|c|c|c|}
\hline \multicolumn{4}{|l|}{$\begin{array}{l}\text { Evidence-based practices } \\
\text { or new interventions }\end{array}$} \\
\hline Dogs management & 0 & 0 & 0 \\
\hline $\begin{array}{l}\text { Caracteristics of dogs: pop. } \\
\text { estimates/of owned }\end{array}$ & 0 & 0 & 0 \\
\hline $\begin{array}{l}\text { Development of } \\
\text { Monitoring and Evaluation } \\
\text { tools }\end{array}$ & 0 & 0 & 0 \\
\hline \multicolumn{4}{|l|}{ Evidence-based advocacy } \\
\hline Disease burden - incidence & 0 & 0 & 0 \\
\hline Cost of illness & 0 & 0 & 0 \\
\hline
\end{tabular}
(Continued)

*PEP: Post-exposure prophylaxis.

to dog depopulation rather than dog mass vaccination $[15,20]$. The re-emergence is believed to be caused by low vaccination coverage in dogs and is coincidental with many socio-economic changes in the country [21]. First, the fiscal decentralization and privatization of the heath care system has led to lower access to health care services for many poor and rural families [22]; second, the uncontrolled dog population growth, particularly in rural areas; third, the development of the transportation network which increases movement of people with their dogs; and fourth, the replacement of concentrated to more expensive purified cell-culture vaccines [23]. A steady decline in incidence has occurred since 2008; there were 1,425 cases in 2012 (57\% in 2007), particularly in endemic provinces (42\%, 51\% and 40\% in 2007 in Guangxi, Guizhou and Guangdong provinces respectively). Documents that analysed the determinants of this decrease were not found.

\section{Level of awareness}

Awareness among policymakers has risen since the rapid and steady increase of human rabies case reports in the past decade (Table 2). The State Council issued official notices in 2009 and 2012 underlining rabies control as a priority and providing program control objectives between 2015 and 2020 [24,25]. Specific rabies-related regulations on roles, responsibilities, and multisectorial cooperation were passed in recent years between the following four ministries [26]. There are (1) the Ministry of Public Security is responsible for the registration of dogs and management, killing of illegal, stray and wild dogs, (2) the Ministry of Agriculture (MoA) for rabid dog control and prevention (vaccination, quarantine), surveillance and response, (3) the State's Food and Drugs Administration for vaccine prequalification and (4) the National Health and Family Planning Commission (NHFPC) for surveillance, PEP and vaccine/immunoglobulin supply in humans. Following these regulations in 2005 the 


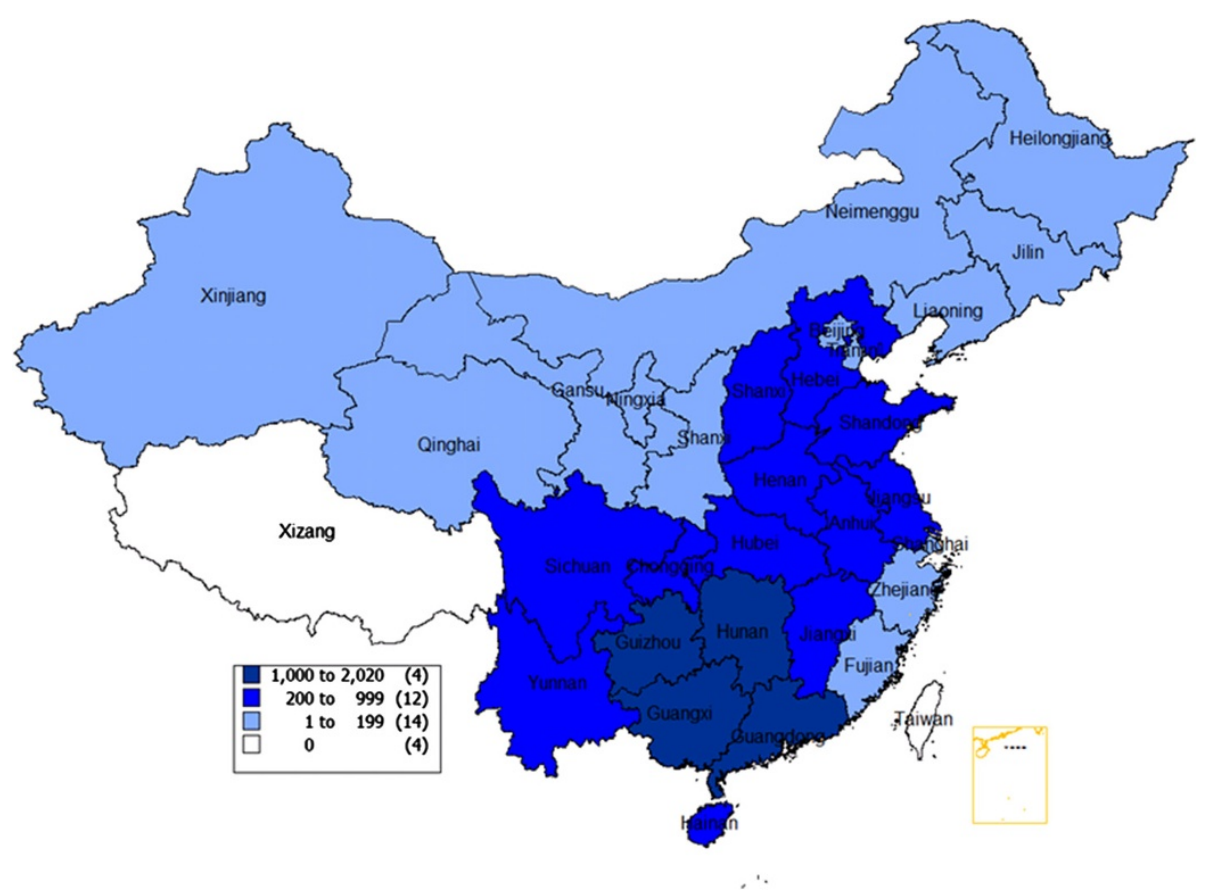

Figure 2 Number of human rabies cases reported in China during 2007-2012.

NHFPC and MoA established a cooperation mechanism in China [27].

All review articles [15,16,19,28-31] showed a dearth of knowledge about rabies in the general public and among health workers - particularly in rural areas. This was based on patchy data collected in limited areas. Si $\mathrm{H}$ et al. reported rabies-related information provided to the public is mainly concentrated in municipal or district Center for Disease Control (CDC)s as opposed to less dissemination in other public settings such as community hospitals, clinics, townships, villages, and police stations [31]. In rural Guizhou or Guangdong provinces poor understanding of rabies among the public persists: only $15 \%$ would clean and disinfect wounds, and $23 \%$ would seek medical treatment rabies clinics following a dog bite. In contrast, high post-exposure vaccination coverage among patients bitten by dogs is present in some of the major cities of the coastal areas (e.g. in Shanghai, 99\%).

\section{Control in humans}

In recent years a series of technical protocols on surveillance, treatment and diagnostic of rabies has been introduced or updated [32-34]. Despite progress in standardizing PEP across the country, authors underscored some implementation gaps: although the standard post-exposure vaccination schedule i.e. Zagreb regimen of rabies vaccine has been approved by the State Food and Drug Administration of China and used in China since 2010, other schedules may still be used [31]. In China, inadequate PEP (incomplete and improper PEP) and some evidence of low quality vaccines have been documented [31]. Seroconversion testing in patients is still performed in many places although it is not recommended for patients completing pre-exposure or PEP [16,35]. For instance the national policy [32] required for instance reasonable availability of PEP clinics - notably in remote areas; unfortunately information is unavailable regarding effective implementation of this requirement. One way to reduce financial cost for many who cannot afford PEP is to adopt an intra-dermal regimen, which is treatment recommended by the World Health Organization (WHO) that has been demonstrated to be as effective as that of intra-muscular administration [36].

According to the 2009 Ministry of Health statistics, China administers 12-15 million rabies vaccine doses annually at a cost of about US\$ 1 billion, making it the world's largest market. A PEP ( US\$ 185/person) and Rabies Immunoglobulin (RIG) treatment costs are beyond the reach of most rural residents [22]. Besides Sanofi and Novartis which registered human rabies vaccines in 1999, there are presently several locally registered manufacturers $(n=13)$. RIG was first registered in 1994 and there are currently 15 registered manufacturers. With the rapid income growth of the Chinese middle class and the fear of rabies, demands for efficient vaccines and their related societal costs will continue to rise unless rabies is controlled in domestic dogs, a situation that has been seen elsewhere in the region (e.g. Vietnam, Thailand, Sri Lanka) [37]. 
Table 2 Laws, regulations and technical documents regarding rabies control issued by China since 1990

\begin{tabular}{|c|c|c|c|}
\hline Type of official documents & Source & Year & Remarks \\
\hline \multicolumn{4}{|l|}{ Legislations } \\
\hline $\begin{array}{l}\text { Law on the Prevention and Control of Infectious } \\
\text { Diseases }\end{array}$ & $\begin{array}{l}\text { Standing Committee of the } \\
\text { National People's Congress }\end{array}$ & 2004 & Included rabies as a priority \\
\hline $\begin{array}{l}\text { The Enforcement Measures for Law on the } \\
\text { Prevention and Control of Infectious Diseases }\end{array}$ & $\begin{array}{l}\text { Approved by State Council, } \\
\text { issued by NHFPC }\end{array}$ & 1991 & $\begin{array}{l}\text { Roles \& responsibilities of different departments } \\
\text { and levels }\end{array}$ \\
\hline $\begin{array}{l}\text { People's Republic of China on Animal Epidemic } \\
\text { Prevention }\end{array}$ & $\begin{array}{l}\text { The Standing Committee of } \\
\text { the National People's Congress }\end{array}$ & 2008 & $\begin{array}{l}\text { Similar with the Law on the prevention and } \\
\text { control of infectious diseases with focus on } \\
\text { principles for animal epidemic prevention. }\end{array}$ \\
\hline \multicolumn{4}{|l|}{ Regulations and technical documents } \\
\hline Rabies Post-Exposure Treatment Standard & NHFPC* & 2009 & Requirements for post-exposure prophylaxis \\
\hline National Rabies Surveillance Program & NHFPC & 2005 & Guidelines for national surveillance in humans \\
\hline $\begin{array}{l}\text { Present Situation of Rabies Prevention and } \\
\text { Control in China }\end{array}$ & NHFPC, MoA, MoPS and SFDA & 2009 & Updates of rabies situation in China \\
\hline Diagnostic Criteria for Rabies & NHFPC & 2008 & Guidelines for laboratory diagnosis \\
\hline $\begin{array}{l}\text { Cooperation Mechanism of Zoonosis Diseases } \\
\text { Prevention and Control among NHFPC and MOA }\end{array}$ & NHFPC and MoA & 2005 & $\begin{array}{l}\text { Work coordination group across ministries. } \\
\text { Director-Generals for lead roles. Information } \\
\text { sharing, meetings, joint outbreak investigations }\end{array}$ \\
\hline $\begin{array}{l}\text { Notice on Strengthening Rabies Prevention and } \\
\text { Control }\end{array}$ & NHFPC, MoA, MoPS and SFDA & 2003 & Updates of rabies situation in China \\
\hline Rabies Prevention and Treatment Standard & MoA & $\begin{array}{l}\text { 2002, } \\
\text { revised in } \\
2006\end{array}$ & $\begin{array}{l}\text { Technical guideline for animal rabies control and } \\
\text { prevention (diagnoses, case definition, reporting } \\
\text { and animal disposal) }\end{array}$ \\
\hline Animal Diseases Surveillance System & MoA & 2009 & $\begin{array}{l}\text { Requirements for animal disease surveillance, for } \\
\text { which rabies is only a part of it }\end{array}$ \\
\hline $\begin{array}{l}\text { National medium and long-term animal } \\
\text { epidemic prevention planning (2012-2020) }\end{array}$ & State Council & 2012 & $\begin{array}{l}\text { Objectives (indicators) for rabies control by } 2015 \\
\text { and } 2020 \text { - No indications on strategies to reach } \\
\text { these objectives }\end{array}$ \\
\hline
\end{tabular}

*Ministry of Agriculture (MoA); National Health and Family Planning Commission (NHFPC); Ministry of Public Security (MoPS); State's Food and Drugs Administration (SFDA).

\section{Control in animals}

The data on dog vaccination rates from a survey in 15 sentinel counties estimated the annual average dog vaccination coverage varied from $1.6 \%$ to $20.4 \%$ for a dog to human ratios of 10.2:100 - 21.8:100 between 2006 and 2009 [38]. However, large disparities exist for these estimates between rural areas and cities or western and coastal provinces. Recent canine vaccination coverage is as high as $93 \%$ in Shanghai and $77 \%$ in some cities of Shandong province (a wealthy coastal province) [21] as opposed to $4 \%$ - $10 \%$ in endemic rural areas of Guizou province $[30,31]$.

Despites the existence of national guideline on rabies control in dogs [39], the country has only enforced national immunization in dogs since 2008 [40]. However, the owners bear the responsibility of the payment of registration and vaccination [41]. Dogs are registered at local police departments, while the rabies vaccines are administrated by Veterinary Services. A coordination mechanism has been proposed but there is no real evidence it is working. Doubts persist regarding the quality of vaccines manufactured in China while officials were concerned about shortages of a canine rabies vaccine required to meet China's need for adequate coverage of its dog population. To date, 20-40 million doses of attenuated vaccines are produced annually, which mainly meet the demands of large cities [41].

\section{Surveillance in humans and dogs}

Human rabies is a notifiable disease in China. Since 2003, China's surveillance for infectious diseases has improved greatly. Surveillance is systematic and nationwide using an innovative hospital and web-based reporting system [42]. In 2005, 15 sentinel counties of six endemic provinces were identified for enhanced rabies surveillance activities which included case reports, postexposure prophylaxis and laboratory testing in humans, and animal reservoir and dog vaccination rates [43]. However, under-reporting and under-recognition occur, which is an inherent problem with any passive surveillance. China CDC also recognizes that many people living in poverty or in rural areas has difficult access to public health services, and that cases might not be properly reported as many peripheral health facilities have no internet access. Underreporting may be higher when it comes to rabies as most victims live in remote and poor 
areas; it was found to be $>35 \%$ based on a capturerecapture study conducted in 2006 in Hunan province [44]. Human rabies is mainly clinically diagnosed. Of 10,866 reported rabid cases during 2005-2010 only 238 (2.2\%) were laboratory-confirmed.

MoA adopted a national protocol for national rabies surveillance in dogs in 2009 [45]; however, for 1,911 human cases detected in China in 2011, only seven rabid dogs were reported, indicating that diagnosis and surveillance for animal rabies is not functioning optimally across the country ( $\mathrm{Tu} \mathrm{C}$, unpublished observation). Joint investigations between public health, veterinary and public security services are rarely seen (FAO, unpublished observation).

\section{Discussion}

Our review was unique in attempting to highlight the strengths and gaps in the rabies control program in China so that potential control activity and related complications could be addressed. Considerable progress has been made to curb the re-emergence of rabies in China since 2005. As a result, the incidence has declined steadily since the peak in 2007. Reasons for this decrease are likely explained by the country's investment in training health professionals on PEP and increasing access to PEP in the countryside (Yin W's unpublished observation). There are few reports of significant investments from local governments of wealthy cities in endemic areas (e.g. Dongguan, Guangdong province) for free dog vaccination campaigns and rural domestic dogs ( Tu C, unpublished observation). Other provincial governments (e.g. Guizhou, Anhui) have recently adopted a health insurance system for rural populations to partially cover PEP costs, although reimbursement rates $(\sim \mathrm{US} \$$ 15 per complete $\mathrm{PEP}$ ) is recognized to be largely insufficient [46].

Chinese authorities at the highest level have identified rabies as a priority to be targeted with a series of progressive objectives until 2020 [25]. More significantly, the public health authorities have recognized that preventing human rabies requires rabies control in the dog population. As such, China has passed policies supporting intersectoral collaborations between ministries and departments involved in the management of the dog population [15]. Technical departments of NHFPC and MoA have paid particular attention to establishing national norms and standards for rabies control and prevention. In addition, they have developed technical guidance by strengthening the laboratory capacity for rabies diagnostics to all provincial public health laboratories in endemic zones. A contributing factor to the potential success of a control program is the existence of a national supply of vaccines for humans and animals as well as human/equine immunoglobulins. It is also crucial for the government to negotiate with local vaccine manufacturers for affordable prices and guaranteed orders of significant amounts of vaccine $[47,48]$.

Despite the increasing volume of publications, legislation and regulations in the recent years, our review points to some major information gaps that provide insight into the level of effectiveness of a nationwide rabies control program in a long run. Undeniably, Chinese policymakers' commitment to control rabies has been a substantial achievement; however, there is a concern that this commitment will fade rapidly when reports of human rabies decrease to a certain level, a situation that already occurred in the late 1980's [15]. We believe that additional evidence is needed to sustain a serious commitment. Indeed, there is a paucity of data regarding the burden of rabies in China, which include estimates of the true incidence and on the relative cost of PEP or disease for the families (e.g. costs of travel for several visits and medical fees) and society. Rabies is thought to be commonly under-reported or under-recognized, resulting in the under-estimate of the true disease burden. Notably, one published households survey on child injury conducted among 319,543 people including 98,335 children aged $<18$ years in Jiangxi province in 2007 estimated that 89 children may have died of animal (mainly dogs) bites while China CDC reported 21 rabies cases (i.e. fourfold underreporting) from the same year and same age group $[2,49]$. Disease Burden data would help provide robust estimates of the cost-benefit ratio of a canine elimination program and accurately determine the most cost-effective strategies for China using a large variety of available options (e.g. free PEP, free dog vaccination, dog population management strategies, decentralization of control, ...etc.) [50].

The second major finding is the presence of information gaps regarding health services or health systems research, economic evaluations, and research that focuses on evidence-based control practices. When it comes to research to improve existing interventions, publications were skewed towards laboratory and virology related works (i.e. new vaccines or diagnostics development). Although connecting researchers with policy makers and control program implementers always has been challenging [51], our review showed that the knowledge generated is non-existent, inferior, or of variable quality, particularly that which could lead to practical action for rabies control. We are under the impression that provincial and more peripheral Bureaus of Health are left to organize improvised control strategies including some that had little evidence for efficiency. Operational research that brings about evidence from the field and could influence practical actions to improve prevention, control and elimination should be encouraged. Examples illustrating the lack of operation-related data include (1) precise estimates and mapping of dog population size/ 
density and their profiles (e.g. rates of roaming or stray dogs) at the most peripheral level, a condition which demonstrates impact (vaccination coverage), develops an effective design and planning of a dog vaccination campaign, and motivates policymakers; and (2) a reduction of human case reports has been observed, however, the challenge is with the NHFPC's ability to measure the impact of interventions that were introduced. Data are lacking to monitor access and quality of PEP on a routine basis. In other words, monitoring and evaluation mechanisms are needed as they become the essential tools for detecting, measuring and interpreting changes overtime. They identify the impact of management activities and subsequent alteration for improvement; (3) developing a research agenda to appropriately inform the policymakers as well as the program managers (e.g. costeffective strategies for dog vaccination and birth control; education and health promotion on rabies targeting children, development of tools and instruments; and an effective strategy for dog population management adapted to local resources and specificities); (4) addressing the issue of a potential sustained rabies wildlife rabies cycle. This highlights the importance of considering some locations for specific surveillance. Only when rabies in dogs is controlled, we can better understand the scale of rabies in wildlife.

Overall, there is a need for more strategic planning to provide a sense of direction and involve concerned people and groups. More importantly this is preparation for progressive steps from uniting the conditions for success (securing funds, correcting the provision of licensed vaccines for humans and dogs, assuring structural changes, raising awareness and community participation, etc.), and designing a roadmap to scaled- up interventions towards a common goal (i.e. elimination of human rabies in China). We also highlight the need for a research agenda addressing the operational needs and constraints in China. In short, this strategy should be a multisectoral effort which is reflected in the form a national field manual for rabies elimination for both the public health and animal health sectors. Such a document should be an evolving guideline that could be initiated based on already existing guiding principles [52] and lessons learned from the field or other countries which are currently engaging in rabies elimination. Furthermore, this document could serve as a model for a long-lasting WHO and FAO's agenda for the "One-Health" concept, a concept that advocates for a close collaboration between the medical and veterinary professions in industrialized and lower-income countries [53,54].

\section{Conclusion}

China has reduced substantially rabies incidence since 2007; however, the authorities' commitment may fade rapidly when reports of human rabies decrease to a certain level. We believe that additional evidence is needed to sustain commitment. The published articles review showed the contrast between an emphasis on knowledgedriven research and the absence of information for effective policies. Monitoring and evaluation mechanisms are lacking to appropriately inform and improve disease control programs. We advocate for strategic planning to address program gaps within the framework of a rabies elimination goal.

\section{Additional file}

Additional file 1: Multilingual abstracts in the six official working languages of the United Nations.

\section{Competing interests}

The authors declare that they have no competing interests.

\section{Authors' contributions}

WY and SV carried out the study design, writing and proofreading. JD and $\mathrm{HZ}$ carried out the data collection and analysis and draft of the manuscript. $C T, J E, F G$ and $H Y$ participated in the provision of data, discussion and review. All authors read and approved the final manuscript.

\section{Acknowledgements}

Members of the Rabies Technical and Advisory Board:

Hong Jie Yu China CDC, Beijing, China.

Wenwu Yin China CDC, Beijing, China.

Qing Tang China CDC, Beijing, China.

Zhenfang Fu College of Veterinary Medicine, The University of Georgia, USA.

Changchun Tu Institute of Military Veterinary, Changchun, China.

Chuanlin Wang The people's hospital of Beijing University, Beijing, China.

Guozhi Li World Society for the Protection of Animals, Beijing, China.

Felix Li Canadian Embassy, Beijing, China.

John Edwards Food and Agriculture Organization, Beijing, China.

Sirenda Vong World Health Organization, Beijing, China.

\section{Author details}

Division of Infectious Diseases, Chinese Center for Disease Control and Prevention, Beijing, China. ${ }^{2}$ Key Laboratory of Surveillance and Early-warning on Infectious Disease, Chinese Center for Disease Control and Prevention, Beijing, China. ${ }^{3}$ World Health Organization, Country Office, Beijing, China. ${ }^{4}$ OIE Reference Laboratory for Rabies, Institute of Military Veterinary, Academy of Military Medical Sciences, Changchun, China. ${ }^{5}$ Food and Agriculture Organization, Beijing, China. ${ }^{6}$ National Institute for viral disease control and prevention, Chinese Center for Disease Control and Prevention, Beijing, China.

Received: 22 August 2013 Accepted: 23 September 2013 Published: 2 October 2013

\section{References}

1. Knobel DL, Cleaveland S, Coleman PG, Fèvre EM, Meltzer MI, Miranda ME, Shaw A, Zinsstag J, Meslin FX: Re-evaluating the burden of rabies in Africa and Asia. Bull World Health Organ 2005, 83(5):360-368. Epub 2005 Jun 24.

2. National Health and Family Planning Commission: Chinese notificable disease surveillance monthly report. [http://www.moh.gov.cn/zhuzhan/yqxx/201304/ b540269c8e5141e6bb2d00ca539bb9f7.shtml]

3. World Health Organization: WHO expert consultation on rabies. World Health Organ Tech Rep Ser 2005, 931:1-88.

4. Lembo T, Hampson K, Kaare MT, Ernest E, Knobel D, Kazwala RR, Haydon DT, Cleaveland S: The feasibility of canine rabies elimination in Africa: dispelling doubts with data. PLoS Negl Trop Dis 2010, 4(2):e626. 
5. Hampson K, Dushoff J, Cleaveland S, Haydon DT, Kaare M, Packer C, Dobson A: Transmission dynamics and prospects for the elimination of canine rabies. PLOS Biol 2009, 7(3):e53.

6. World Health Organization: Strategies for the control and elimination of rabies in Asia. Report of the WHO interregional consultation, July 2001. WHO/CDS/ CSR/EPH/2002.8. [http://www.who.int/rabies/en/Strategies_for_the_control_ and_elimination_of_rabies_in_Asia.pdf]

7. Lembo T, Attlan M, Bourhy H, Cleaveland S, Costa P, de Balogh K, Dodet B, Fooks AR, Hiby E, Leanes F, Meslin FX, Miranda ME, Müller T, Nel LH, Rupprecht CE, Tordo N, Tumpey A, Wandeler A, Briggs DJ: Renewed global partnerships and redesigned roadmaps for rabies prevention and control. Vet Med Int 2011, 2011:923149.

8. Belotto A, Leanes LF, Schneider MC, Tamayo H, Correa E: Overview of rabies in the Americas. Virus Res 2005, 111(1):5-12

9. Gongal G, Wright AE: Human rabies in the WHO Southeast Asia region: forward steps for elimination. Adv Prev Med 2011, 2011:383870.

10. United National Theme Group on Health. [http://www.un.org/en/ globalissues/health/index.shtml]

11. Food and Agriculture Organization ECTAD: [http://www.fao.org/docrep/015/ an331e/an331e00.pdf]

12. Coleman $P G$, Dye $C$ : Immunization coverage required to prevent outbreaks of dog rabies. Vaccine 1996, 14(3):185-186.

13. Zinsstag J, Dürr S, Penny MA, Mindekem R, Roth F, Menendez Gonzalez S, Naissengar S, Hattendorf J: Transmission dynamics and economics of rabies control in dogs and humans in an African city. Proc Natl Acad Sci USA 2009, 106(35):14996-15001.

14. Liu Y, Zhang S, Zhao J, Zhang F, Hu R: Isolation of Irkut Virus from a Murina leucogaster Bat in China. PLoS Negl Trop Dis 2013, 7(3):e2097.

15. Hu R, Tang Q, Tang J, Fooks AR: Rabies in China: an update. Vector Borne Zoonotic Dis 2009, 9(1):1-12.

16. Wu X, Hu R, Zhang Y, Dong G, Rupprecht CE: Reemerging rabies and lack of systemic surveillance in People's Republic of China. Emerg Infect Dis 2009, 15(8):1159-1164.

17. Zhang S, Tang Q, Wu X, Liu Y, Zhang F, Rupprecht CE, Hu R: Rabies in ferret badgers, southeastern China. Emerg Infect Dis 2009, 15(6):946-949.

18. Liu Y, Zhang S, Wu X, Zhao J, Hou Y, Zhang F, Velasco-Villa A, Rupprecht CE, Hu R: Ferret badger rabies origin and its revisited importance as potential source of rabies transmission in Southeast China. BMC Infect Dis 2010, 10:234.

19. Yu J, Li H, Tang Q, Rayner S, Han N, Guo Z, Liu H, Adams J, Fang W, Tao X, Wang S, Liang G: The spatial and temporal dynamics of rabies in China. PLoS Negl Trop Dis 2012, 6(5):e1640.

20. Zhang YZ, Xiong CL, Xiao DL, Jiang RJ, Wang ZX, Zhang LZ, Fu ZF: Human rabies in China. Emerg Infect Dis 2005, 11(12):1983-1984.

21. Song M, Tang Q, Wang DM, Mo ZJ, Guo SH, Li H, Tao XY, Rupprecht CE, Feng ZJ, Liang GD: Epidemiological investigations of human rabies in China. BMC Infect Dis 2009, 9:210.

22. Kaufman JA: China's heath care system and avian influenza preparedness. J Infect Dis 2008, 197(Suppl 1):S7-S13.

23. Song M, Tang Q, Xu Z, Li H, Wang DM, Mo ZJ, Gao LD, Guo SH, Zhu FC, Hu $\mathrm{DL}$, Wang $X J$ : Analysis on the factors related to rabies epidemic in China, in 2005. Zhonghua Liu Xing Bing Xue Za Zhi 2006, 27(11):956-959. in Chinese with English abstract.

24. State's Food and Drugs Administration. [http://www.sfda.gov.cn/WS01/ CL0056/48237.html]

25. Ministry of Agriculture: The National Medium and Long-term Animal Epidemic Prevention Planning (2012-2020). [http://www.moa.gov.cn/zwllm/ghjh/ 201205/t20120530_2678977.htm]

26. National Health and Family Planning Commission: Cooperation Mechanism of Zoonosis Diseases Prevention and Control among MOH and MOA. [http:// www.moh.gov.cn/publicfiles/business/htmlfiles/mohbgt/pw10511/200804/ 27463.htm]

27. National Health and Family Planning Commission: Notice on Strengthening Rabies Prevention and Control in 2003. [http://www.moh.gov.cn/publicfiles/ business/htmlfiles/mohbgt/pw10302/200804/33487.htm]

28. Tang Q: Study on the characteristics and typing of rabies pathogen. Zhonghua Liu Xing Bing Xue Za Zhi 2008, 29(3):302-305 (in Chinese).

29. Tang X, Luo M, Zhang S, Fooks AR, Hu R, Tu C: Pivotal role of dogs in rabies transmission. China. Emerg Infect Dis 2005, 11(12):1970-1972.
30. Wang X, Ding S, Li Z, Wang L, Kou Z, Feng K, Wang L, Wu X, Rupprecht CE: Human rabies epidemiology in Shandong Province, China. Jpn J Infect Dis 2010, 63(5):323-326.

31. Si H, Guo ZM, Hao YT, Liu YG, Zhang DM, Rao SQ, Lu JH: Rabies trend in China (1990-2007) and post-exposure prophylaxis in the Guangdong province. BMC Infect Dis 2008, 8:113.

32. National Health and Family Planning Commission: Rabies Post-Exposure Treatment Standard. [http://www.moh.gov.cn/mohbgt/s10695/200912/ 45090.shtml]

33. National Health and Family Planning Commission: National Rabies Surveillance Program. [http://www.moh.gov.cn/zhuzhan/zcjd/201304/ 51c041d5c7cf4b8ea03819d43c25c23a.shtml]

34. National Health and Family Planning Commission: Diagnostic Criteria for Rabies. [http://www.moh.gov.cn/zwgkzt/s9491/200901/38806.shtml]

35. Manning SE, Rupprecht CE, Fishbein D, Hanlon CA, Lumlertdacha B, Guerra M, Meltzer MI, Dhankhar P, Vaidya SA, Jenkins SR, Sun B, Hull HF, Advisory Committee on Immunization Practices Centers for Disease Control and Prevention (CDC): Human rabies prevention--United States, 2008: recommendations of the Advisory Committee on Immunization Practices. MMWR Recomm Rep 2008, 57(RR-3):1-28.

36. World Health Organization: Current WHO Guide for Rabies Pre and Post-exposure Treatment in Humans; 2002 [http://www.who.int/rabies/en/WHO_guide_ rabies_pre_post_exp_treat_humans.pdf]

37. The Human Rabies Vaccine Market in China: General Biologic's Instablog. [online] 29 June 2009. [http://seekingalpha.com/instablog/745341-generalbiologic/191578-the-human-rabies-vaccine-market-in-china]

38. Zhou H, Man TF, Li Q, Yin WW: Surveillance of human rabies in China, 2009. Disease Suveillance 2010, 25:12.

39. Ministry of Agriculture: Technical Guideline for Rabies Prevention and Treatment. [http://www.moa.gov.cn/zwllm/nybz/200803/ t20080304_1028651.htm]

40. The Central People's Government of People's Republic of China: The Notice of Strengthening of Rabies Vaccination jointly published by $\mathrm{MOH}$ and MOA. [http://www.gov.cn/gzdt/2008-01/18/content_862422.htm]

41. Hu RL, Fooks AR, Zhang SF, Liu Y, Zhang F: Inferior rabies vaccine quality and low immunization coverage in dogs (Canis familiaris) in China. Epidemiol Infect 2008, 136(11):1556-1563.

42. Yang WZ, Li ZJ, Lan YJ, Wang JF, Ma JQ, Jin LM, Sun Q, LV W, Lai SJ, Liao YL, Hu MB: A nationwide web-based automated system for early outbreak detection and rapid response in China. Western Pacific Surveillance and Response Journal 2011 [http://www.wpro.who.int/wpsar/ volumes/02/1/en/]

43. Chinese Centre for Disease Control and Prevention: National Rabies Surveillance Programm (Provisial 2005). [http://www.chinacdc.cn/jkzt/crb/kqb/ kqbjc/200508/t20050810_24178.htm]

44. Yu HJ, Luo HM, Luo SB, Li XS, Xie JM, Kaisheng W, Qingting Z: Rabies investigation in Leiyang city, Hunan province. Chinese Journal of Epidemiology 2006, 27(3):252 (in Chinese).

45. Ministry of Agriculture: The Notice for Animal Disease Surveillance Plan in 2009. [http://www.moa.gov.cn/zwllm/ghjh/200902/t20090201_1214895.htm].

46. The notice of the cost of rabies post exposure vaccination was listed in New Rural Cooperative Medical Expenses Category. [http://www.gdxnh.cn/html/ zcwj/200911101831.html]

47. Wang $C$, Zhang $X$, Song $Q$, Tang $K$ : Promising rabies vaccine for postexposure prophylaxis in developing countries, a purified vero cell vaccine produced in china. Clin Vaccine Immunol 2010, 17(4):688-690.

48. Liu H, Huang G, Tang Q, Li J, Cao S, Fu C, Cao Q, Liu B, Pan H, Wang M: The immunogenicity and safety of vaccination with purified Vero cell rabies vaccine (PVRV) in China under a 2-1-1 regimen. Hum Vaccin 2011, 7(2):220-224. Epub 2011 Feb 1.

49. Research team of child injury survey in Jiangxi: Epidemiological survey of child injury in Jiangxi province. Chin Prev Med 2007, 8(5):521-526 (in Chinese).

50. World Health Organization: Adding a vaccine to a national immunization programme: decision and implementation; 2005 [http://whqlibdoc.who.int/ hq/2005/WHO_IVB_05.18.pdf]

51. Jansen MW, van Oers HA, Kok G, de Vries NK: Public health: disconnections between policy, practice and research. Health Res Policy Syst 2010, 8:37. 
52. Blue print for rabies control and prevention: Rabies blue print. [http://www. rabiesblueprint.com/?lang=en]

53. Murphy FA: Emerging zoonoses: the challenge for public health and biodefence. Prev Vet Med 2008, 86:2016-2223.

54. Zinsstag J, Shelling E, Wyss K, Mahamat MB: Potential of cooperation between human and animal health to strengthen health systems. Lancet 2005, 366:2142-2145.

doi:10.1186/2049-9957-2-23

Cite this article as: Yin et al: Challenges and needs for China to

eliminate rabies. Infectious Diseases of poverty 2013 2:23.

\section{Submit your next manuscript to BioMed Central} and take full advantage of:

- Convenient online submission

- Thorough peer review

- No space constraints or color figure charges

- Immediate publication on acceptance

- Inclusion in PubMed, CAS, Scopus and Google Scholar

- Research which is freely available for redistribution 